\title{
Propensity to pedagogical activity in the structure of professional choice of high school students
}

\author{
Mariam Nogerova, Rakhima Malkarova*, Azamat Sozaev \\ Kabardino-Balkar State University named after H.M. Berbekov 360004 Nalchik, Russian \\ Federation
}

\begin{abstract}
The relevance of the study of the problem of professional selfdetermination of high school students and features of the choice of profession by modern graduates is substantiated. The degree of expression of pedagogical inclinations in the structure of professional personality types and types of professional activity of graduates as a result of research of high school students is established. Methods were used: a questionnaire of professional inclinations (L. Yovaishi's method in G. V. Rezapkina's modification), the method "Determination of professional personality type" (J. V. Rezapkina's method). Holland in the modification Of G. V. Resorcinol), methods - methods "Matrix choice of profession" G. V. Resorcinol. It was found that the most common professional personality type among high school students with pedagogical inclinations is the social type. Respondents with a tendency to pedagogical activity often have a harmonious structure of professional choice, namely, a high indicator in which all three components of professional choice (inclinations, interests, type) are clearly expressed.
\end{abstract}

\section{Introduction}

In connection with the changes in the social and economic spheres of society, the resolution of the problem of choosing a profession at the present stage of development of psychological and pedagogical Sciences and society is gaining relevance. Issues related to the formation of man as a subject of labor, are constantly the object of attention from scientists in the field of psychology, pedagogy of sociology. However, it should be noted that at this stage of development of Sciences the theoretical aspects of the problem of professional choice are still insufficiently developed, there is no common understanding of the situation of choice of profession.

In the works of many scientists who develop the problem of professional development of a person, the phenomenon of professional choice and the process of decision-making about the future profession is considered through the prism of professional self-

\footnotetext{
*Corresponding author: $\underline{\text { mtd61@mail.ru }}$
} 
determination $[1,2,3,4,5]$. V. I. Kryukova believes that professional choice is a complex, highly individual, complex process, including internal and external factors, based on a combination of needs, interests, motives, personal characteristics, images of himself in the profession and under the influence of parents and society [1].

The problems associated with professional choice, self-determination, self-realization of a person in the implementation of a particular type of professional activity are of great importance today, because the requirements for a professional from society are constantly changing. Among these requirements are the compliance of personal characteristics of the activity, the ability to formulate goals and to achieve them, independence, the ability to exercise free choice. In order to make the right decision when choosing a profession, you need to get acquainted with the requirements put forward by the profession to the person's personality, and you must take into account your individual psychological characteristics in order to correlate them with these requirements. In studies of psychologists and teachers noted that self-realization in the profession depends largely on the existing interests, aptitudes and aptitude of man.

At this stage of development of the company, the requirements for graduates continue to grow. Especially high are the requirements for the willingness to make an informed, independent decision about the choice of profession, which he also feels the need. For the successful course of the initial stages of professional self-determination it is necessary to develop an effective algorithm of social, psychological and pedagogical support of students. Its absence leads to the fact that many young people are not psychologically ready to make a responsible decision on the choice of profession.

Along with the changes in the social and economic spheres of society, the pedagogical sphere of labor is being transformed. The requirements for the quality of teachers ' training continue to grow. The increased requirements to the level of professional training of personnel actualize the problems of professional orientation of young people, as well as the problems of matching the choice of profession to the personal characteristics of a person [2]. The formation of professional interest is closely related to aptitudes, abilities, motives. Propensity to pedagogical activity is understood as the predisposition of the person formed in the process of social experience, to professional activity of the "person-person" type, connected with education and training.

The current economic and political situation makes increasing demands on the individual psycho-physiological characteristics of the teacher. This problem is particularly acute in the field of teacher training, personal characteristics of which often do not correspond to the desirable characteristics indicated in the teacher's profession. Interest in the teaching profession has fallen sharply in recent years. Some authors attribute this to a decrease in the prestige of this profession. According to Filippov A. A. "In recent years, the social status of teachers in the minds of Russians has decreased dramatically. As various studies show, the profession of teacher in modern Russia has become very low-prestige. According to all-Russian researchers in the field of psychology and pedagogy, young people do not seek to choose the profession of teacher" [3]. The majority of respondents interviewed by the author consider the main reasons for the lack of prestige of the profession "teacher": too high requirements of the state, zero working conditions and low wages.

In psychological and pedagogical literature some significant regulators of a choice of profession are widely covered, however the problem of inclinations is considered very poorly. There are practically no studies examining the role of pedagogical aptitudes in the process of professional choice by high school students. Meanwhile, the propensity to absorb the desire and desire to engage in a particular activity professionally. Usually, the structure of propensity combines a deep interest in any object and a steady desire to implement the activities aimed at this object. The presence of propensity implies the 
existence of a stable desire not just for the contemplation of the object of interest, but for the desire to carry out activities. Hence, the propensity to pedagogical activity suggest the presence in the structure of the human nature of these same aspirations and desires to engage in educational activities. Their absence in the structure of professionally significant qualities of the teacher causes a high probability that the functions of pedagogical activity will not be performed at the highest level.

Hence, taking into account the inclinations present in the structure of individual characteristics, as well as the level of their severity could be more likely to provide the right professional choice, leading to successful self-realization in the profession. That is, if applicants with pedagogical inclinations, will take this into account in determining their professional path, there will be an increase in the number of teachers, personal characteristics of which correspond to the ongoing teaching activities. This would undoubtedly lead to an improvement in the quality of education. However, in the psychological and pedagogical literature there are very few works devoted to this problem.

Since this problem is the least studied, it determined the choice of our topic. What role do pedagogical aptitudes play in the choice of teaching profession by high school students, we have to establish in our study.

Thus, the aim of the study is to determine the place of pedagogical inclinations in the structure of the professional type of personality of high school students. Under the structure of professional choice, we understand the relationship of its components, such as professional aptitude, professional personality type.

\section{Research Methods and Techniques}

To diagnose the degree of severity of these components, such research methods as theoretical analysis, synthesis and generalization of psycho-pedagogical literature, questionnaires, mathematical methods of data processing, quantitative and qualitative analysis were used. Methodological tools included a questionnaire professional inclinations (method L. Lovisi in modification of the G. V. Resorcinol), the method of "Definition of professional personality type" (procedure J. Holland in the modification of G. V. Resorcinol), methods - methods "Matrix choice of profession" G. V. Resorcinol.

The study was conducted in MKOU "SOSH" S. p. Germenchik URVAN district, MKOU "SOSH N2 im. M. Abaev," p Upper Balkaria, the Chereksky district, SECONDARY school №2 of S. p. Zhemtala in the Cherek district, MKOU "SOSH №8 im. V. Sokaeva" S. p. O. Hasan'ya the city of Nalchik. It was attended by students of 11 classes, the total number of subjects was 125 people.

The first stage was carried out diagnosis of the severity of professional dispositions using the method of L. Jovaisa in modification of the G. V. Resorcinol and identified respondents with a penchant for the teaching profession. Further, this group of respondents was determined by the professional type of personality and the corresponding types of activity by the method of J. Holland in the modification of G. V. Resorcinol, the technique of "Matrix choice of profession" G. V. Resorcinol. The diagnostic results are presented in tables $1,2,3$.

The psychological concept developed by J. Holland, connected the theory of personality with the theory of choice of profession. In modification of the G. V. Resorcinol this technique allowed us to determine what type of person is each of the subjects which of the six occupational environments allocated in this method, the most suitable for him. Based on the concept of J. Holland created a classification of professions and identified six professionally oriented personality types: realistic, intellectual, social, conventional, entrepreneurial and artistic. 


\section{Results}

Table 1 presents the results of the diagnosis of the professional type of personality of high school students, the results of the analysis of each type for the adequacy of pedagogical activity, the degree of severity of the professional type in a group of respondents with pedagogical inclinations.

Table 1. Percentage of respondents with weak, medium, strong degree of pedagogical inclinations in the structure of professional personality types

\begin{tabular}{|l|c|c|c|}
\hline $\begin{array}{c}\text { Degree of manifestation } \\
\text { Personality type }\end{array}$ & $\begin{array}{l}\text { Related to } \\
\text { personality type }\end{array}$ & Strongly & Average \\
\hline Realistic & & $5 \%$ & $25 \%$ \\
\hline Intelligent & & $3 \%$ & $38 \%$ \\
\hline Social & $0,8 \%$ & $10,5 \%$ & $49 \%$ \\
\hline Office & & $7 \%$ & $33 \%$ \\
\hline Entrepreneurial & $1,6 \%$ & $7 \%$ & $42 \%$ \\
\hline Artistic & & $71 \%$ \\
\hline
\end{tabular}

Almost a quarter of the subjects with pedagogical aptitudes (24\%) have a pronounced social professional type, as much as the average expressed social type. Only $2 \%$ of respondents with a pronounced intellectual type are inclined to pedagogical activity. The same number of respondents with pedagogical inclinations belong to a pronounced entrepreneurial type. Y43\% $(3 \%+38 \%)$ subjects with intellectual depomedrone tendency is expressed strongly and moderately, y36\%predstavitelskogo professional type have a medium level of intensity. As for the artistic type, $7 \%$ of the subjects have pronounced inclinations, and $40 \%$ are at an average level.

Table 2 presents the results of the diagnosis of the severity of the types of professional activity of high school students, the results of the analysis of each type for the adequacy of pedagogical inclinations.

Table 2. Percentage of respondents with weak, medium, strong degree of pedagogical inclinations in the structure of types of activity

\begin{tabular}{|l|c|c|l|}
\hline Type of activity & Strongly & Average & Weakly \\
\hline Teaching & $6,5 \%$ & $27,5 \%$ & $36 \%$ \\
\hline Research & & $8 \%$ & $35 \%$ \\
\hline Practical & & $10 \%$ & $56 \%$ \\
\hline Aesthetic & $1,6 \%$ & $2,4 \%$ & $24 \%$ \\
\hline Extreme & & $4 \%$ & $45 \%$ \\
\hline Planning and economic & & & $33,6 \%$ \\
\hline
\end{tabular}

This group of subjects was $34 \%$ of the sample population, from них $27,5 \%$ has an average degree of inclination for teaching activities, $6.5 \%$, or a strongly expressed tendency.

Next, we identified respondents whose professional choice is adequate to the prevailing in the structure of their professional choice inclinations. The quantitative distribution of respondents by individual types of inclinations is presented in table 3 .

Table 3. Respondents who have chosen a profession in accordance with the prevailing inclinations 


\begin{tabular}{|l|c|}
\hline \multicolumn{1}{|c|}{ Type of inclinations } & $\begin{array}{c}\text { Respondents who have made an } \\
\text { adequate choice of profession }\end{array}$ \\
\hline Tendencies to pedagogical activity & $62 \%$ \\
\hline Inclination to research activities & $0 \%$ \\
\hline Propensity to practice & $33 \%$ \\
\hline The tendency to aesthetic types of activities & $0 \%$ \\
\hline Propensity to extreme activities & $12,5 \%$ \\
\hline Propensity to plan-economic activities & $40 \%$ \\
\hline
\end{tabular}

As can be seen from table 3,62\% of respondents inclined to pedagogical activity made an adequate choice of profession. Further down is a group of respondents with a penchant for planning and economic activities. Of these, $40 \%$ of respondents made a professional choice adequate to their inclinations. $33 \%$ of respondents inclined to practical activity made the choice of profession corresponding to their inclinations. Among respondents prone to extreme activities adequate choice of profession was recorded in $12.5 \%$ of the subjects. Among those who were diagnosed with a tendency to research and a tendency to aesthetic activities, respondents who made an adequate choice of profession was not found.

Further, in order to identify the place of pedagogical inclinations in choosing the profession of a teacher, we examined the structure of the professional choice of specific subjects with pedagogical inclinations. Having analyzed in detail the answers of the subjects according to each of the methods, we got 4 types of professional choice structure: - Type I - a structure in which all three components of professional choice are clearly expressed (inclinations, interests, type).

- Type II - a structure in which pedagogical inclinations and professional type are pronounced, and professional interests are weakly expressed.

- Type III - a structure with pronounced pedagogical inclinations and professional interests, and the professional type is weakly expressed.

- Type IV - pedagogical inclinations are pronounced, and professional interests and type are weakly expressed.

Type I is characterized by the fact that each of the components of the structure of professional choice distinguished in our study is quite pronounced. This is the most harmonious structure of all highlighted in this study. Pronounced pedagogical inclinations interact with a pronounced professional type adequate to pedagogical activity, and is supported by the intensity of professional interest in the pedagogical sphere of activity. Type II suggests the high severity of only two components of the structure of professional choice, namely, pedagogical inclinations and professional type. Professional interests adequate to pedagogical inclinations in this structure are expressed at a low level or not at all. Therefore, the choice of a pedagogical profession by a representative of this type is presumably due only to pedagogical inclinations and a professional type. Type III has some similarities with Type II, since it is also characterized by the severity of not each of the three components of the structure of professional choice, but only two of them - pedagogical tendencies and interest in pedagogical activity. In this type of structure, the least pronounced professional type is adequate to pedagogical inclinations. Therefore, the choice of a pedagogical profession as a representative of this type is presumably due only to pedagogical inclinations and professional interest. Type IV differs in that it is the most disharmonious structure of all four identified in this study. So this structure of professional choice is named because it is characterized by the high severity of only one component of the structure - pedagogical inclinations. The two remaining components of professional choice are either not expressed at all, or expressed at the lowest levels. Subject to the choice of the teaching profession by the majority of representatives of this type, it can be assumed that this choice is determined by pronounced 
propensities

for

pedagogical

activity.

The percentage ratio of the distribution of respondents with pedagogical inclinations by type of structure of professional choice is presented in table 4 .

Table 4. Percentage distribution of respondents with pedagogical inclinations by type of structure of professional choice

\begin{tabular}{|l|l|c|c|c|c|}
\hline \multicolumn{1}{|c|}{ Type of structure } & Type I & Type II & Type III & Type IV \\
\hline $\begin{array}{l}\text { Groups by } \\
\text { choice of } \\
\text { profession }\end{array}$ & $\begin{array}{l}\text { Choosing a teaching } \\
\text { profession }\end{array}$ & $50 \%$ & $27 \%$ & $23 \%$ & $12 \%$ \\
\cline { 2 - 6 } & $\begin{array}{l}\text { Those who choose a non- } \\
\text { teaching profession }\end{array}$ & $6 \%$ & - & $19 \%$ & $75 \%$ \\
\hline
\end{tabular}

Based on the data in the table, we can say that $50 \%$ of respondents with a harmonious structure of professional choice - Type I, chose the teaching profession. Among those who did not choose the pedagogical, only $6 \%$ have a harmonious structure of professional choice, which we named Type I. $27 \%$ of the subjects with Type II chose the pedagogical profession. Among those who prefer a different field of professional activity, there are no respondents with Type II. Type III was found in $23 \%$ of subjects who chose a pedagogical profession, and $19 \%$ - who chose a different field of activity. And finally, the fourth type of structure was found in $12 \%$ of subjects who chose a pedagogical profession, and in $75 \%$ of those who did not choose a pedagogical sphere.

\section{Summary}

Thus, the analysis of the results shows that the most common type of inclinations among high school students is a tendency to work with people, involving professional activities related to management, training, education, service. The most common professional personality type among high school students with pedagogical aptitudes is the social type. The most adequate pedagogical inclinations professional type of personality - social - and is the most common among high school students with pronounced pedagogical inclinations.Among the subjects with pedagogical inclinations, respondents with a professional type, adequate inclinations, compared with the subjects prone to other activities are more common. That is, respondents with a tendency to pedagogical activity often have a harmonious structure of professional choice.

\section{References}

1. V.I. Kryukova, Psychological factors of choice of technical professions in modern conditions (Moscow, 2005)

2. K.A. Adishirin-Zade, Vector science TSU. 1(1), 7-9 (2010)

3. A.A. Filippov, Social and professional status of a school teacher in modern Russia (2014)

4. E.I. Pilyugina, M.D. Ivanova, Young scientist. 15, 619-623 (2017)

5. C. Rogers, Freedom to learn for the 80"s. (Toronto-Sydney, New York, 1983) 